\title{
Characterization of reservoir sediment under water with differential pressure-sensored flat dilatometer and piezo-penetrometer
}

\author{
Jui-Ting Lee $\cdot$ Chien-Chih Wang $\cdot$ Yen-Te Ho $\cdot$ \\ An-Bin Huang
}

Received: 20 January 2012/ Accepted: 3 September 2012/Published online: 5 February 2013

(C) The Author(s) 2013. This article is published with open access at Springerlink.com

\begin{abstract}
The unusually strong typhoons and heavy rainfalls occurred recently in Taiwan have caused major landslides in many reservoir catch basins. The debris from these landslides eventually settled in the reservoir and turned into mud. From soil mechanics point of view, the mud immediately in front of the dam where the reservoir is usually the deepest is a very young, normally consolidated or under-consolidated fine-grained soil. The engineering properties of the reservoir mud are important parameters in the planning and design of schemes to remove the mud. Yet, our knowledge in this regard is very limited. For some of the major reservoirs in Taiwan, the mud is often under more than $40 \mathrm{~m}$ of water. How to conduct effective geotechnical site characterization under these circumstances is a challenge. The authors developed techniques to incorporate differential pressure measurements in flat dilatometer $(\triangle \mathrm{DMT})$ and piezo-penetrometer $(\Delta \mathrm{Pu})$ tests to facilitate in situ measurements under water in a reservoir. A series of field $\triangle \mathrm{DMT}$ and $\Delta \mathrm{Pu}$ tests along with representative soil sampling were conducted at Tsengwen Reservoir in southern Taiwan. The paper describes the techniques of $\triangle \mathrm{DMT}$ and $\Delta \mathrm{Pu}$ tests, interpretation of available test data to obtain the engineering properties of
\end{abstract}

\author{
J.-T. Lee $(\bowtie)$ C C.-C. Wang · Y.-T. Ho · A.-B. Huang \\ Department of Civil Engineering, \\ National Chiao-Tung University, \\ Hsinchu, Taiwan \\ e-mail: ruiting.cv92g@nctu.edu.tw \\ C.-C. Wang \\ e-mail: cc.wang.nctu@gmail.com \\ Y.-T. Ho \\ e-mail: ytho@mail.nctu.edu.tw \\ A.-B. Huang \\ e-mail: abhuang@mail.nctu.edu.tw
}

the reservoir mud, and discusses implications in the future site characterization of reservoir mud.

Keywords Differential pressure $\cdot$ DMT $\cdot$ Mud · Piezometer $\cdot$ Reservoir $\cdot$ Sediment

\section{Introduction}

Rainfalls brought in by typhoons passing Taiwan are becoming extreme in the past decade. The intense rainfall resulted in flooding in flat land and landslides in the mountain areas. Many landslides occurred in the watershed of reservoirs. The debris from landslides eventually settled in the reservoir and turned into mud. This has caused severe impacts on operation and useful life of the reservoirs. Typhoon Aere of 2004 brought an average rainfall of $1,000 \mathrm{~mm}$ in the watershed of Shihmen Reservoir in northern Taiwan and resulted in an estimated 28 million $\mathrm{m}^{3}$ of sediment in the reservoir which had a total storage capacity of 238 million $\mathrm{m}^{3}$ before the event. Typhoon Morakot passed southern Taiwan in August 2009 and had an accumulated rainfall close to $3,000 \mathrm{~mm}$ in the watershed of Tsengwen Reservoir of southern Taiwan (Fig. 1). Widespread landslides brought approximately 90 million $\mathrm{m}^{3}$ of sediment to the reservoir. Tsengwen Reservoir, the largest hydro-project of its kind in Taiwan, had a storage capacity close to 600 million $\mathrm{m}^{3}$ prior to Typhoon Morakot. Engineering properties of the sediment are imperative in developing schemes to remove the sediment and for safety evaluation of the related hydraulic structures. From soil mechanics point of view, reservoir sediment immediately in front of the dam where the reservoir is usually the deepest is a young, water-transported fine-grained soil deposit that is normally or under-consolidated. In addition to basic physical 


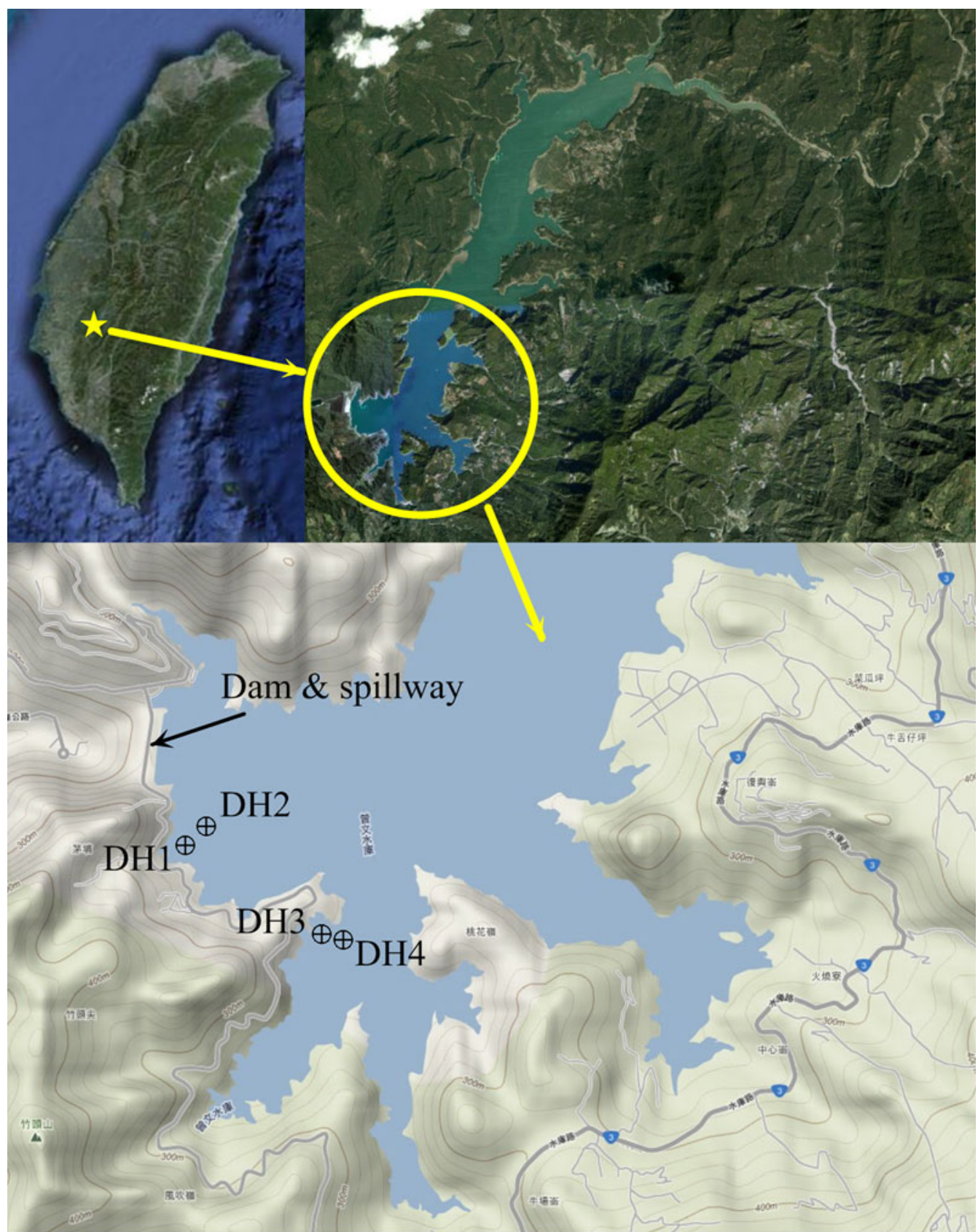

Fig. 1 Tsengwen Reservoir and boring locations

properties, the state of consolidation and density of the sediment are of major concerns.

The depth of water above reservoir sediment at Tsengwen varies and can be close to or exceed $40 \mathrm{~m}$, depending on the water level. Because of the shortage of water supply, it is not possible to drain the reservoir for maintenance or soil testing purposes. Water content of the sediment may be close to or exceed its liquid limit (LL), making undisturbed soil sampling not practical.

The flat dilatometer is a stainless steel blade (approximately $95 \mathrm{~mm}$ wide, $240 \mathrm{~mm}$ long, and $15 \mathrm{~mm}$ thick) having a flat, circular steel membrane (60 $\mathrm{mm}$ diameter) mounted flush on one side as shown in Fig. 2 [7]. The blade is connected to a control unit on the ground surface by a pneumatic-electrical tubing to transmit air pressure and electric signal. The control unit is equipped with a pressure regulator, pressure gage(s), an audio-visual signal, and vent valves.

The blade, connected to the tip of a string of push rods, is advanced into the ground using push rigs normally used for cone penetration test (CPT) or drill rigs. The test starts by inserting the dilatometer into the ground. Soon after 


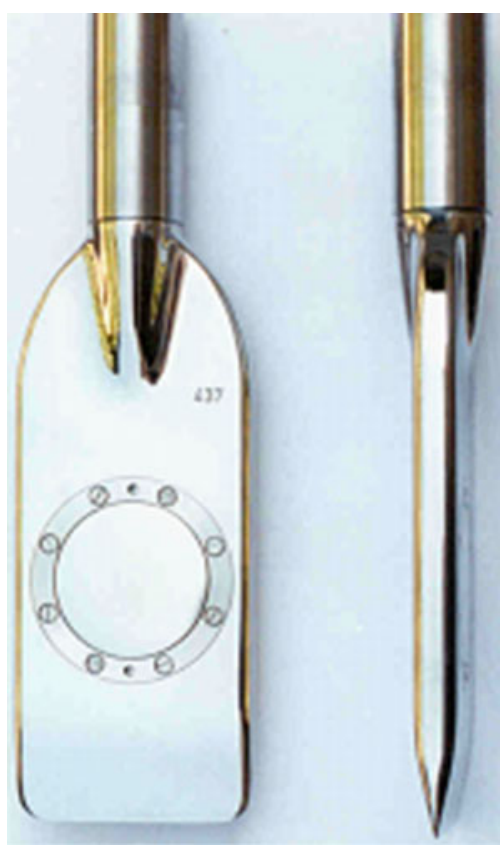

Fig. 2 The flat dilatometer-front and side view (from Marchetti et al. [7])

penetration, by use of the control unit, the operator inflates the membrane and takes two readings in about 1 min: the $A$-pressure, required to just to move the membrane against the soil ("lift-off"), and the $B$-pressure, required to move the center of the membrane $1.1 \mathrm{~mm}$ against the soil. A third reading $C$ ("closing pressure") can also optionally be taken by slowly deflating the membrane soon after $B$ is reached. The blade is then advanced into the ground of one depth increment (typically $20 \mathrm{~cm}$ ), and the procedure for taking $A, B$ readings repeated at each depth. The pressure readings $A, B$ are then corrected by the values $\Delta A, \Delta B$ determined by calibration to take into account the membrane stiffness and converted into $p_{0}, p_{1}$. The interpretation evolved by first identifying three "intermediate" DMT parameters [5]: the material index $I_{\mathrm{D}}$, horizontal stress index $K_{\mathrm{D}}$, and dilatometer modulus $E_{\mathrm{D}}$ which are defined as:

$$
\begin{aligned}
& I_{\mathrm{D}}=\left(p_{1}-p_{0}\right) /\left(p_{0}-u_{0}\right) \\
& K_{\mathrm{D}}=\left(p_{0}-u_{0}\right) / \sigma_{\text {vo }}^{\prime} \\
& E_{\mathrm{D}}=34.7\left(p_{1}-p_{0}\right)
\end{aligned}
$$

where $u_{0}=$ pre-insertion pore pressure $\sigma_{\mathrm{vo}}^{\prime}=$ pre-insertion effective overburden stress

Many empirical equations have been developed over the years that relate intermediate DMT parameters to soil engineering properties $[1,7]$. The material unit weight, $\gamma$, and its ratio to that of water, $\gamma_{w}$ or $\gamma / \gamma_{w}$, can be inferred through DMT modulus, $E_{\mathrm{D}}$, and material index, $I_{\mathrm{D}}$, as shown in Fig. 3. Methods, as will be presented later, have been proposed to estimate the over consolidation ratio

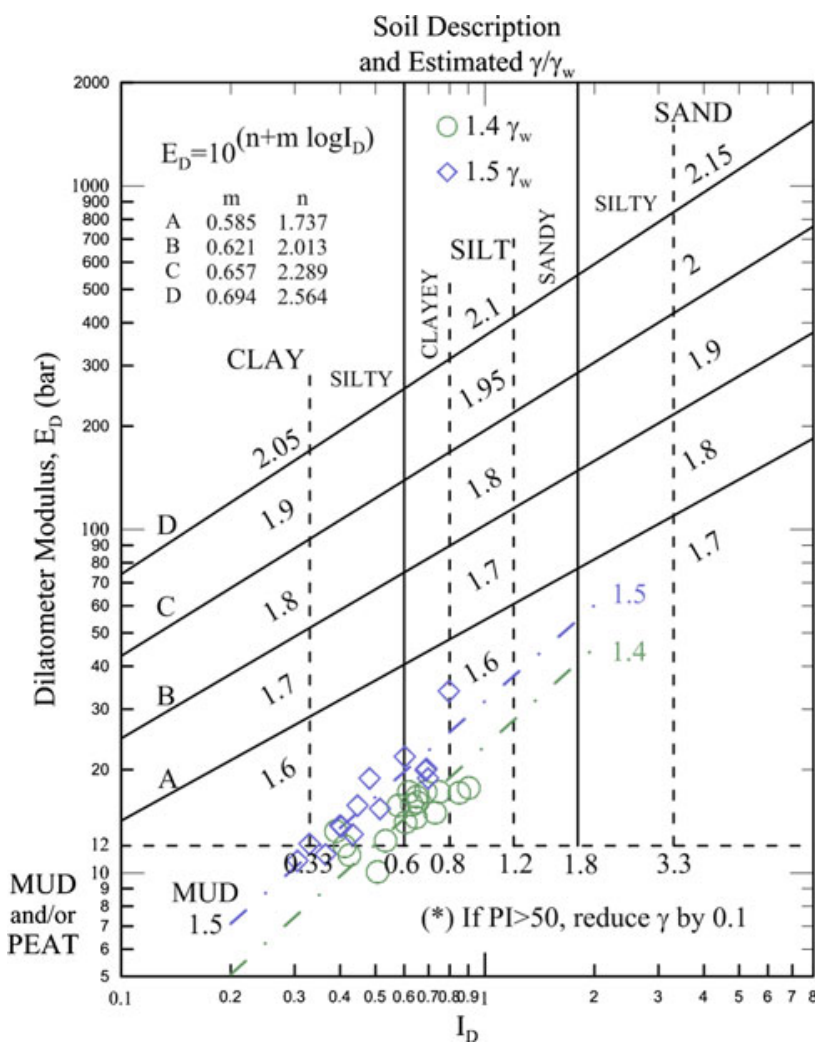

Fig. 3 Inferring soil unit weight through ED and ID. (after Marchetti and Crapps [6])

(OCR) from $K_{\mathrm{D}}$, for soils with OCR $\geq 1$ [4]. Empirical equations to determine undrained shear strength based on $\sigma_{\mathrm{vo}}^{\prime}$ and $K_{\mathrm{D}}$ for cohesive soils have also been suggested [7].

The DMT blade and the testing control system were simple and rugged, suitable for testing in cohesive and cohesionless soils with a wide range of consistency and density. For the empirical equations to perform properly, the values of the in situ equilibrium pore pressure, $u_{0}$, and of the vertical effective stress, $\sigma_{\mathrm{vo}}^{\prime}$ prior to blade insertion have to be known, at least approximately. The available empirical correlations, however, do not extend to finegrained soils with $\gamma / \gamma_{\mathrm{w}}<1.6$ or OCR $<1$.

Huang et al. [3] reported the use of the Marchetti flat dilatometer (DMT) coupled with time-domain reflectometry (TDR) to characterize sediment at Shihmen Reservoir in northern Taiwan. The TDR device consisted of a pulse generator, an oscilloscope, a co-axial transmission cable, and a measurement waveguide. The pulse generator sent an electromagnetic pulse along the transmission line, and the oscilloscope was used to observe the returning reflections from the measurement waveguide. The 800-mm-long TDR waveguide had an outside diameter of $35.6 \mathrm{~mm}$, the same size as the connection rod behind the DMT blade. It was fitted immediately behind the DMT blade. The values of $\gamma / \gamma_{\mathrm{w}}$ of the sediment surrounding the TDR waveguide were 
inferred from the electromagnetic measurements. The TDR-DMT was performed under a maximum of $80 \mathrm{~m}$ of water. Because of the low strength/density of reservoir sediment, the lift-off $(A)$ and $1.1 \mathrm{~mm}$ expansion pressure $(B)$ readings from DMT could be just slightly larger than the hydrostatic pressure. Also, the $\Delta B$ obtained from field calibration with $90 \mathrm{~m}$ of pneumatic tubing installed between the DMT blade and the control unit was a relatively large value in comparison with the $B$-pressure readings. After deducting the DMT membrane stiffness corrections, $\left(p_{1}-p_{0}\right)$ of Eqs. (1) and (3) could be close to or below 0 . The $E_{\mathrm{D}}$ and $I_{\mathrm{D}}$ readings reported by Huang et al. [3] tend to fluctuate and became negative, in the upper $10 \mathrm{~m}$ of the sediment where the material was extremely soft. The soil unit weight in that depth range could only be inferred from TDR readings. The use of TDR requires threading the relative thick coaxial cable through drill rods and that significantly hampers the field DMT operation. Also, TDR was not able to reflect the excess pore water pressure within an under-consolidated soil deposit.

Because of the above-described drawbacks, the authors equipped the DMT and a piezo-penetrometer with an optical fiber differential pressure transducer to perform the field tests. The modification enabled the DMT $A$ and $B$ readings as well as the pore water pressure from piezopenetrometer be taken against the hydrostatic pressure. The DMT with differential pressure measurements will be referred to as $\triangle \mathrm{DMT}$. The piezo-penetrometer equipped with a differential pressure transducer will be called $\Delta \mathrm{Pu}$. Representative reservoir sediment samples were taken with a bailer typically used to take water samples at designated depths. With these data, it was possible to extend the existing DMT interpretation charts to consider soils similar to the tested reservoir sediment. This paper describes the basic principles of the optical fiber differential pressure transducer and field operations with $\triangle \mathrm{DMT}$ and $\Delta \mathrm{Pu}$. A series of $\triangle \mathrm{DMT}$ and $\Delta \mathrm{Pu}$ tests were performed at Tsengwen Reservoir. Interpretations of these test results are presented, and implications in extending the applications of DMT in extremely soft soils under water are discussed.

\section{The optical fiber differential pressure transducer}

In contrast to a conventional pressure transducer, the deflection of the transducer diaphragm in response to pressure variation is sensored by an optical fiber Bragg grating (FBG) pierced through the diaphragm as shown in Fig. 4. The diaphragm separates the reference and input pressure chambers. When used as a gauge pressure transducer, the reference chamber is exposed to the atmospheric pressure. The reference chamber is connected to a

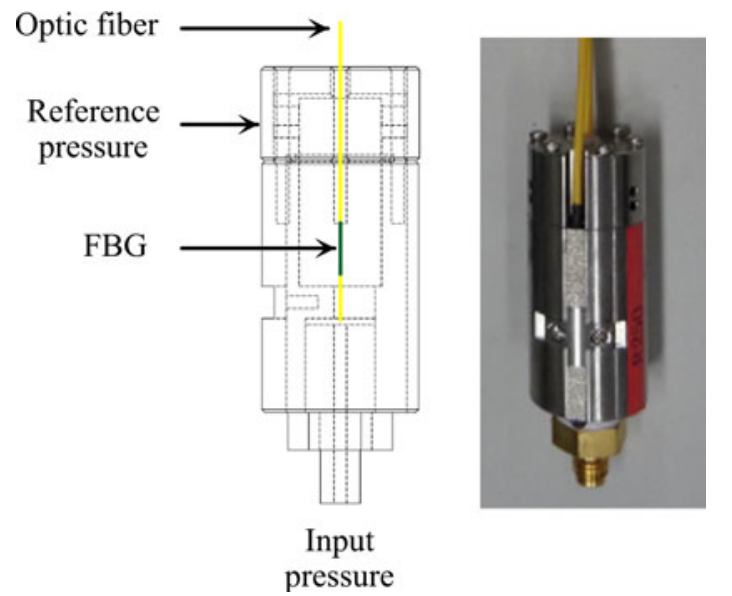

Fig. 4 The FBG differential pressure transducer

reference pressure when used as a differential pressure transducer. Sensitivity and range of the pressure transducer can be adjusted by changing the thickness and diameter of the diaphragm. A separate FBG sealed inside of a stainless steel tube, placed alongside the pressure transducers, was used as a temperature sensor for temperature compensation. The FBG differential pressure transducer had a full range of $500 \mathrm{kPa}$ and a resolution of $0.08 \mathrm{kPa}$. The same FBG differential pressure transducer was used in both the $\triangle \mathrm{DMT}$ and the $\triangle \mathrm{Pu}$ tests. The FBG is immune to short circuit and electromagnetic interference, making the transducer especially suitable for underwater soil testing. Details of the FBG pressure transducer can be found in [2].

\section{The $\triangle \mathrm{DMT}$}

For the $\triangle \mathrm{DMT}$, an FBG differential pressure transducer was placed at $450 \mathrm{~mm}$ above the center of the DMT diaphragm as shown in Fig. 5. The effects of air friction in the pneumatic tubing during diaphragm expansion were minimized. A coupler was used to divert the diaphragm expansion pressure into the FBG differential pressure transducer. The coupler and FBG differential pressure transducer were all situated inside the hollow drill rod.

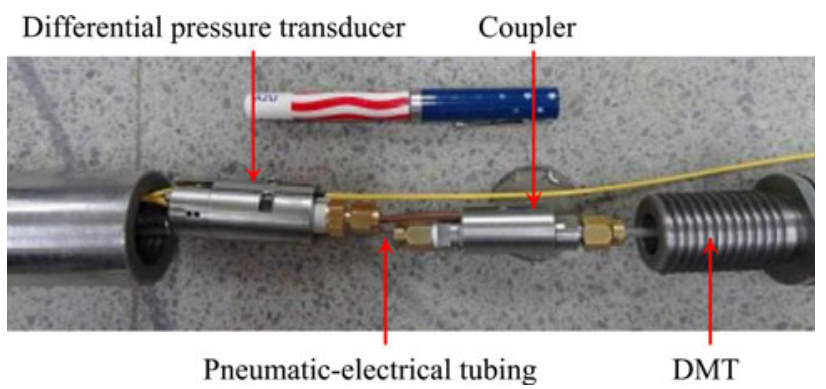

Fig. 5 The $\triangle \mathrm{DMT}$ 
Drainage holes drilled in the reference pressure chamber facilitate its connection to the hydrostatic pressure, $u_{0}$, where $u_{0}=\gamma_{\mathrm{w}} z_{\mathrm{w}}$ and $z_{\mathrm{w}}$ was the depth of water above the reference pressure chamber. With this setup, the $\triangle \mathrm{DMT}$ obtained $\left(A-u_{0}\right)$ and $\left(B-u_{0}\right)$ directly. The $A$ and $B$ readings were not affected by the depth of water, and there was no need to estimate $u_{0}$ in the interpretation of test data. The $\left(A-u_{0}\right)$ and $\left(B-u_{0}\right)$ readings were adjusted for the $450 \mathrm{~mm}$ water head difference when presenting the test data.

FBG differential pressure transducer had its own computer readout unit that records data automatically. In performing the $\triangle \mathrm{DMT}$, the diaphragm calibration and expansion readings were taken at both the pressure gage of the control unit as in the conventional DMT and FBG readout unit.

\section{The $\Delta \mathrm{Pu}$}

The $\Delta \mathrm{Pu}$ used the same FBG differential pressure transducer and also situated at $450 \mathrm{~mm}$ above the porous element. The penetrometer had a diameter of $35.6 \mathrm{~mm}$, the same as a standard cone penetrometer. A 20-mm-wide porous element made of porous plastic with $100-\mu \mathrm{m}$ pore size. The porous element was placed at $15 \mathrm{~mm}$ behind the face of the penetrometer tip that had a $60^{\circ}$ tip. Figure 6 shows the picture of an assembled $\Delta \mathrm{Pu}$. The $\Delta \mathrm{Pu}$ measures excess pore water pressure, $\Delta u$, directly against $u_{0}$. Again, the readings are not affected by the depth of water.

In performing the $\Delta \mathrm{Pu}$, the penetrometer was lowered to the designated depth and the change of $\Delta u$ was recorded automatically by the computer. The data logging process ceased when $\Delta u$ reached a stabilized value.

\section{Field testing and sampling}

The field tests and soil sampling reported herein were performed at boring locations designated as DH1 to DH4

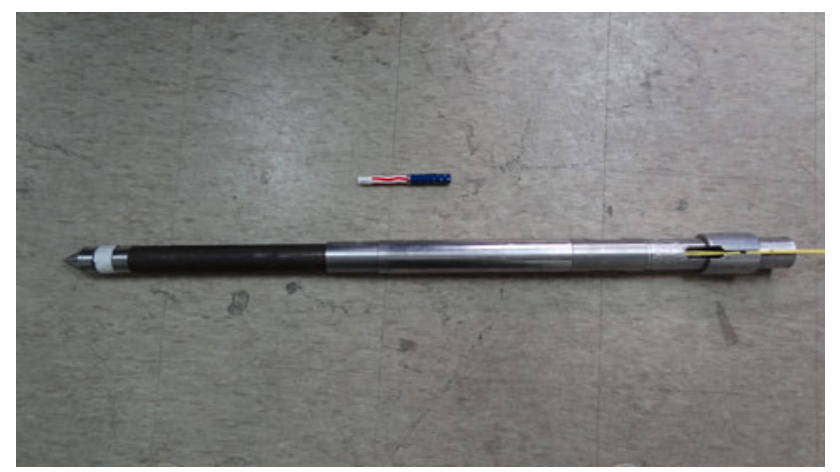

Fig. 6 The $\Delta \mathrm{Pu}$

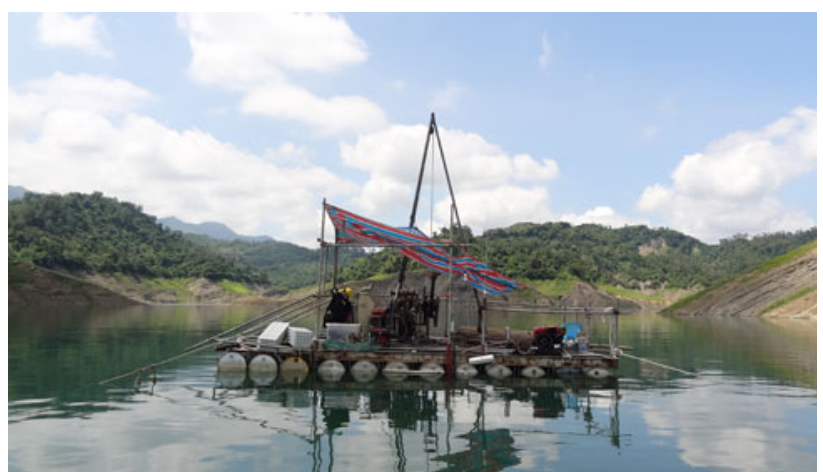

Fig. 7 The barge mount drill rig

shown in Fig. 1. All boreholes were located within the reservoir. The field testing and sampling took place in the month of July 2011. The operation was conducted using a drill rig mounted on a barge. The $\triangle \mathrm{DMT}$ or $\Delta \mathrm{Pu}$ probe was attached to a string of A-sized drill rods. The weight of drill rods was enough to offset the buoyancy and provide reaction force to penetrate the test probe $10 \mathrm{~m}$ into the sediment. A portable drill rig mounted on a barge was used to hold the drill rods from the water surface as shown in Fig. 7. The DMT tubing along with the optical fiber was taped to the outside of the drill rods through an adaptor and then connected to their respective control unit on the barge. All drainage tunnels of the reservoir were shut down during the field tests to prevent fluctuation of the water surface elevation.

There were two major layers of reservoir sediment. The top layer, located from elevation 176 to 167, was deposited after Typhoon Morakot of 2009. Representative soil samples from the top layer were taken using a bailer sampler while the borehole was kept open using a steel casing. The sediment was soft enough that the weight of the drill rod and water sampler could penetrate into the sediment with their own weight from the bottom of the borehole. Upon retrieving, the sediment sample was sealed in a glass bottle and brought to the laboratory for physical property tests. The sediment from below elevation 167 (the bottom layer) to the bedrock at elevation 146 was deposited since completion of the reservoir in 1970s and prior to Typhoon Morakot. The bottom layer was relatively stiff, and soil samples were taken using a thin-wall tube sampler. Figure 8 shows the profile of soil plasticity and water content according to laboratory tests on reservoir sediment samples. The reservoir sediment consisted mostly of silty clay and occasional low plastic silt.

As shown in Fig. 8, essentially all the top layer reservoir sediment (depth 0-9 m, elevation 176-167) samples had water content in excess of the respective liquid limit (LL). The water content approached twice the value of their LL toward the surface of the top sediment layer. For the 


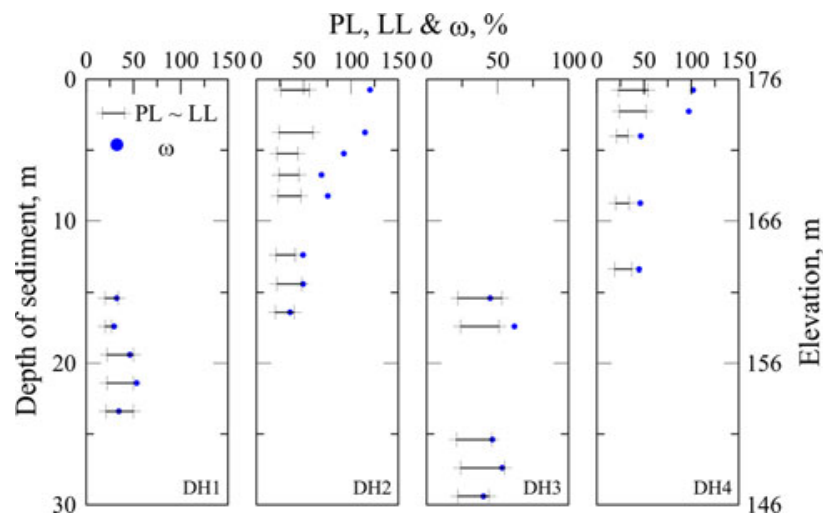

Fig. 8 Plasticity and water content of the reservoir sediment

"older" bottom sediment layer, the water contents were generally less than their LL. The profiles of $\gamma$ denoted in Fig. 9 are consistent with the change in water contents shown in Fig. 8. The top layer had $\gamma$ ranging from 2 times of the water density $\gamma_{\mathrm{w}}$ to as low as $1.4 \gamma_{\mathrm{w}}$. For the most part of the bottom layer, $\gamma$ was close to $2 \gamma_{w}$.

\section{Field test results}

The field tests to be reported herein consisted of DMT with differential pressure readings $(\triangle \mathrm{DMT})$ and differential pressure piezo-penetrometer $(\Delta \mathrm{Pu})$ tests in the top sediment layer. A soft stainless steel membrane was used in all the $\Delta$ DMT. Figure 10 shows the fully assembled $\Delta$ DMT before lowering into the water. Table 1 shows the depth of water above the top layer sediment and membrane stiffness calibrations $\Delta A$ (negative pressure required to suck the membrane to the surface of the DMT blade) and $\Delta B$ (pressure required to expand the membrane $1.1 \mathrm{~mm}$ ) according to pressure gage on the DMT control unit and differential pressure transducers. Two profiles of $\triangle \mathrm{DMT}$

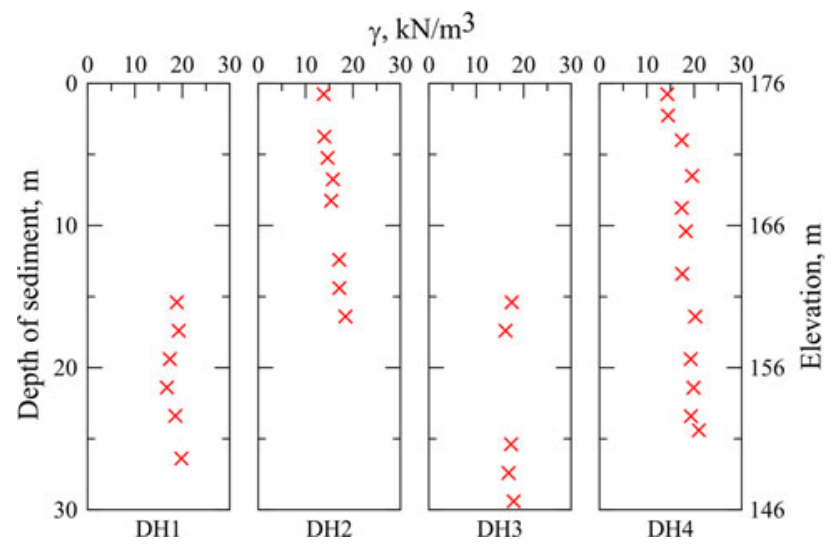

Fig. 9 Saturated unit weight of the sediment

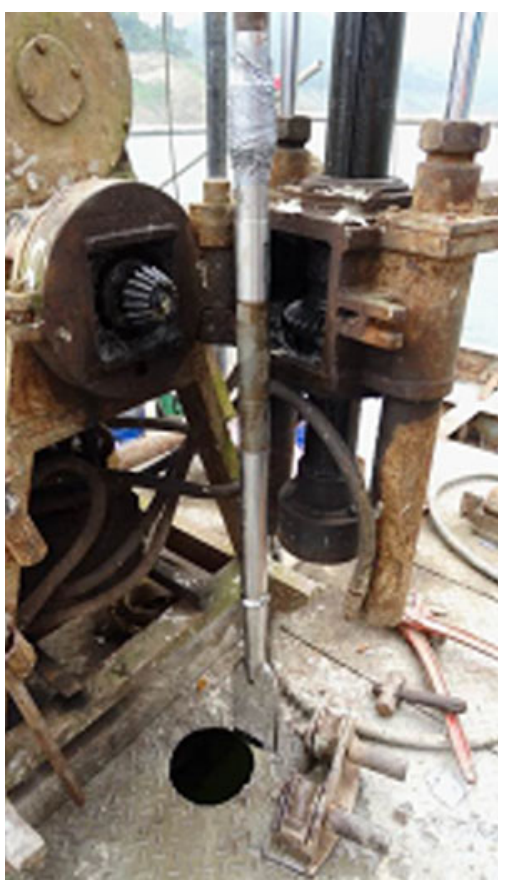

Fig. 10 The fully assembled $\Delta D M T$

were performed at test locations $\mathrm{DH} 1$ and $\mathrm{DH} 2$. The $\triangle$ DMT was conducted at 20 -cm intervals.

The pneumatic tubing used in this series of tests ranged from 50 to $100 \mathrm{~m}$ long, depending on the depth of water at the time of field test. The membrane calibration described in Table 1 was performed with all the tubing connected just prior to $\triangle \mathrm{DMT}$. While the range of $\Delta B$ was within the range of acceptable values, the friction of air passing through the long pneumatic tubing may be significant enough to cause the errors in both $B$ and $\Delta B$ readings for DMT in soft sediment. These errors resulted in $p_{0}$ larger than those in $p_{1}$.

The $p_{0}$ and $p_{1}$ in Fig. 11 correspond to $A$ and $B$ readings after correction for the membrane stiffness and pressure

Table $1 \Delta$ DMT membrane calibration

\begin{tabular}{|c|c|c|c|c|c|}
\hline \multirow[t]{2}{*}{ Location } & \multirow{2}{*}{$\begin{array}{l}\text { Depth of water } \\
\text { (m) }\end{array}$} & \multicolumn{2}{|l|}{$\Delta A$} & \multicolumn{2}{|l|}{$\Delta B$} \\
\hline & & $t^{*}$, bar & $d^{+}$, bar & $t^{*}$, bar & $d^{+}$, bar \\
\hline DH1-1 & 18.1 & -0.2 & -0.07 & 0.5 & 0.22 \\
\hline DH1-2 & 18.6 & -0.2 & -0.09 & 0.5 & 0.25 \\
\hline DH2-1 & 17.1 & -0.2 & -0.17 & 0.75 & 0.33 \\
\hline DH2-2 & 17.5 & -0.2 & -0.19 & 0.7 & 0.35 \\
\hline DH3 & 15.0 & -0.1 & -0.04 & 0.45 & 0.15 \\
\hline DH4 & 37.7 & -0.2 & -0.13 & 0.55 & 0.29 \\
\hline
\end{tabular}




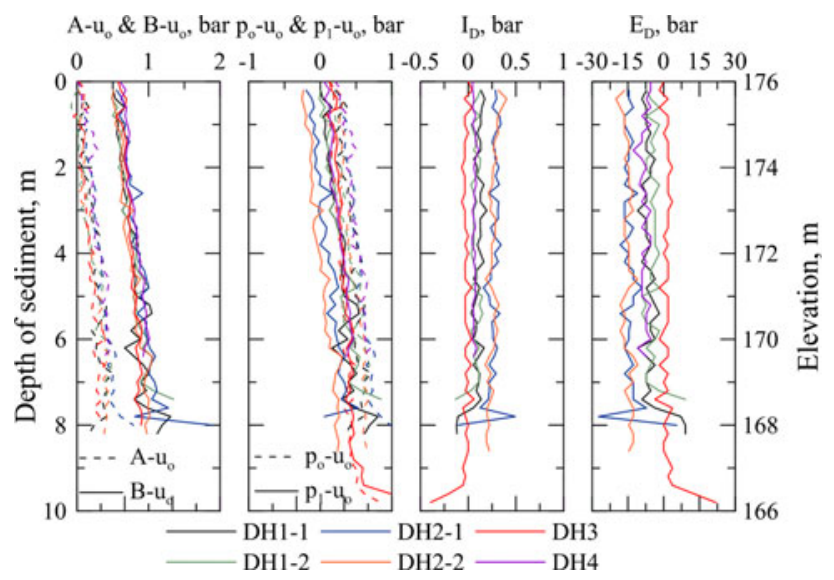

Fig. 11 Results according to DMT control console pressure gage readings

gage zero readings. The results in Fig. 11 show unusually low or negative $I_{\mathrm{D}}$ and negative $E_{\mathrm{D}}$. The abnormality can be traced to the low $p_{1}$ in comparison with $p_{0}$ as shown in Fig. 11. The relatively low $p_{1}$ is in turn caused by the large $\Delta B$ readings shown in Table 1 .

Significant discrepancies in $\Delta B$ were noticed between the readings taken from the pressure gage in the DMT control console ( $t$ reading) and those from the differential pressure transducer ( $d$ reading) located immediately above the DMT blade. In most cases, the $t$ readings were twice the value of $d$ readings. Figure 11 shows the available DMT data according to the $A$ and $B$ readings taken from the control console and estimated $\mathrm{u}_{\mathrm{o}}$ from depth of water, $z_{\mathrm{w}}$ (i.e., $u_{0}=\gamma_{\mathrm{w}} z_{\mathrm{w}}$ ). Two profiles of DMT were performed at DH1 (denoted as DH1-1 and DH1-2) and DH2 (denoted as DH2-1 and DH2-2).

Figure 12 shows the same $\Delta \mathrm{DMT}$ results using readings from the differential pressure transducer. The $I_{\mathrm{D}}$ values fall in a range that is compatible for clay and silt. The $E_{\mathrm{D}}$ values also conform to a soft soil deposit. With the results

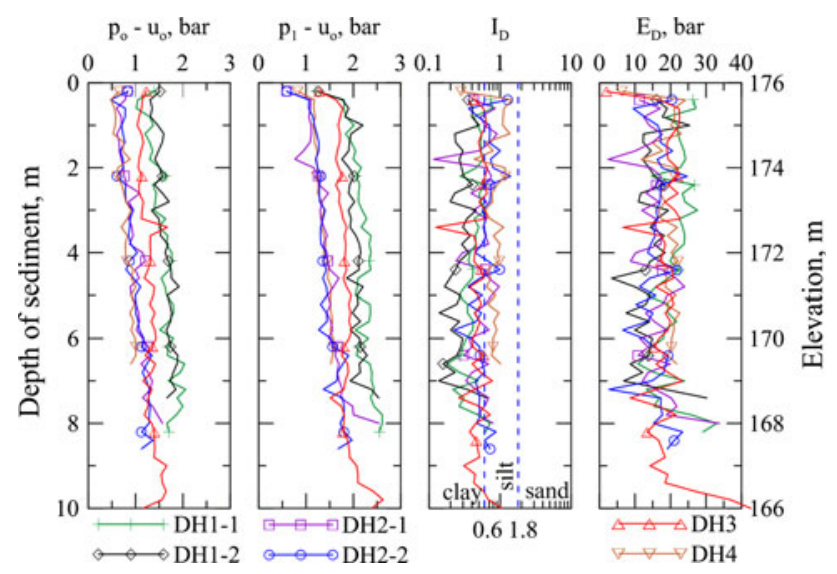

Fig. 12 Results according to $\triangle \mathrm{DMT}$ from differential pressure transducer readings depicted in Figs. 9 and 12, two lines that correspond to $\gamma /$ $\gamma_{\mathrm{w}} 1.4$ and 1.5, respectively, are added in Fig. 3. These correlations are proposed to estimate soil unit weight for similar reservoir sediment based on $I_{\mathrm{D}}$ and $E_{\mathrm{D}}$ from $\Delta \mathrm{DMT}$.

If the horizontal stress index, $K_{\mathrm{D}}$, is to be invoked in the interpretation of $\triangle \mathrm{DMT}$, it is necessary to determine the pre-insertion effective overburden stress $\left(\sigma_{v o}^{\prime}\right)$ at the depth of $\triangle \mathrm{DMT}$ as indicated in Eq. (2), and

$\sigma_{v o}^{\prime}=\sigma_{v o}-u=\sigma_{v o}-u_{0}-\Delta u$

where $u$ is the pore water pressure that includes hydrostatic pressure $u_{0}\left(=\gamma_{\mathrm{w}} \mathrm{Z}_{\mathrm{w}}\right)$ and $\Delta u$ which is the excess pore water pressure yet to be dissipated. If the soil is not fully consolidated, $\Delta u>0$. Consider the young age of the reservoir sediment, it was not certain if the sediment was completely consolidated under its own weight. Or, $\Delta u$ in Eq. (4) may not be zero. To verify the state of consolidation, $\Delta \mathrm{Pu}$ was performed in the top sediment layer in $\mathrm{DH} 4$ at $50-\mathrm{cm}$ intervals. The piezometer was lowed to the designated depth, and the decay of excess pore water pressure was monitored. It took approximately $30 \mathrm{~min}$ for the excess pore pressure $(\Delta u)$ reading to reach a stabilized value. The results of the $\Delta \mathrm{Pu}$ in terms of stabilized $\Delta u$ versus depth are presented in Fig. 13. To establish the profile of $\sigma_{\mathrm{vo}}^{\prime}$ for the determination of $K_{\mathrm{D}}$, a representative $\gamma / \gamma_{\mathrm{w}}$ value of 1.5 was used and $\sigma_{\mathrm{vo}}=\gamma z_{\mathrm{s}}=1.5 \gamma_{\mathrm{w}} z_{\mathrm{s}}$, where $z_{\mathrm{s}}$ is the depth of sediment. Figure 14 demonstrates the profiles of the effective overburden stress $\left(\sigma_{\mathrm{vo}}^{\prime}\right)$ according to $\Delta \mathrm{Pu}$, and the expected effective overburden stress after the excess pore water pressure is fully dissipated based on the assumed soil unit weight $\left(\sigma_{\mathrm{vof}}^{\prime}=0.5 \gamma_{\mathrm{w}} z_{\mathrm{s}}\right)$. For the top, under-consolidated sediment layer, $\sigma_{\mathrm{vo}}^{\prime}$ is also the pre-consolidation stress, $\sigma_{\mathrm{p}}^{\prime}$.

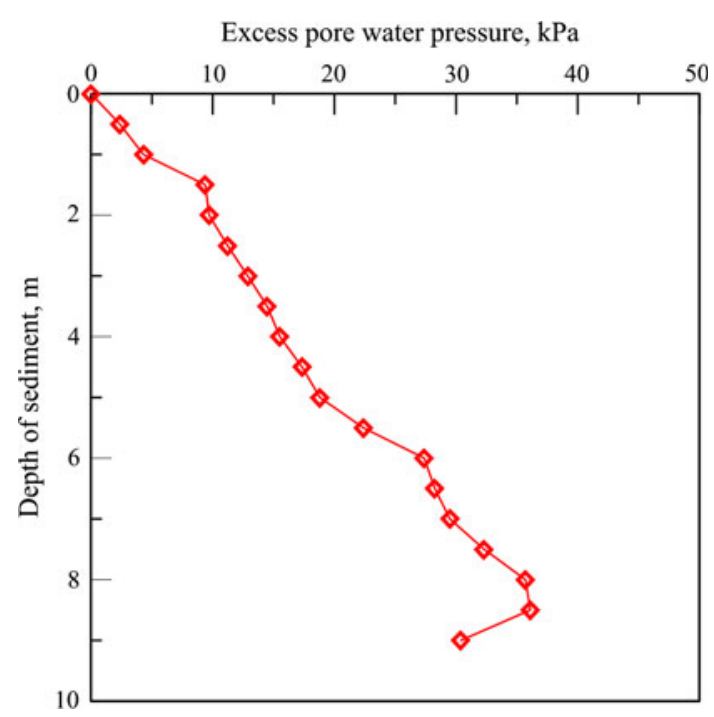

Fig. 13 Excess pore water pressure from DH4 


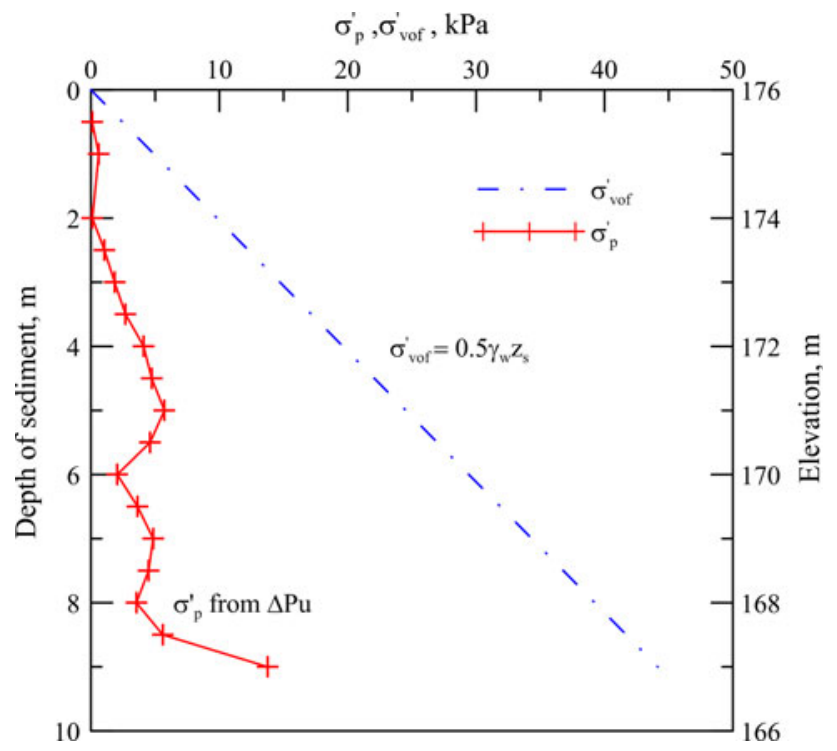

Fig. 14 Overburden and pre-consolidation stress profile

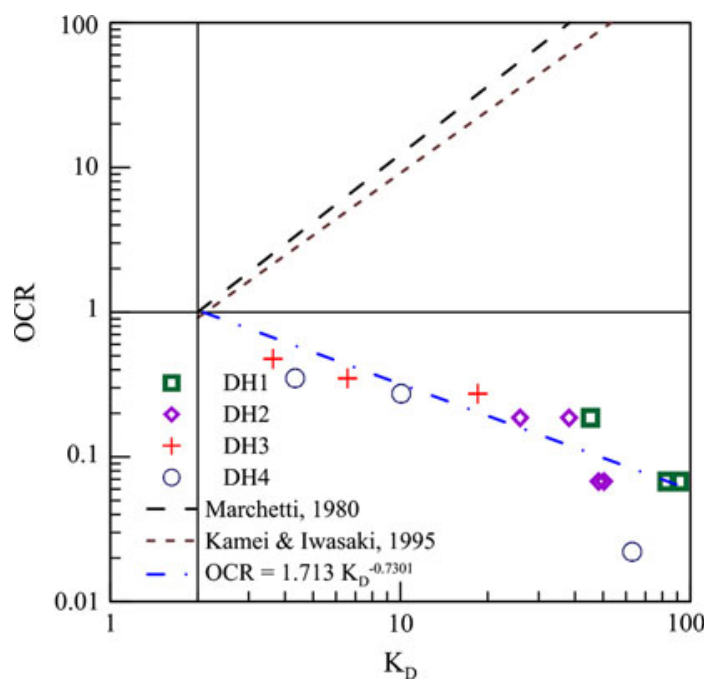

Fig. 15 Correlation between $K_{\mathrm{D}}$ and OCR

The over consolidation ratio (OCR) is defined as $\sigma_{\mathrm{p}}^{\prime} /$ $\sigma_{\text {vof }}^{\prime}$. According to this definition, OCR values for the top sediment layer are extremely low. A plot of available $K_{\mathrm{D}}$ versus OCR is shown in Fig. 15. In this Figure, $K_{\mathrm{D}}$ was computed using Eqs. (2) and (4) and $\Delta u$ values taken from the $\Delta \mathrm{Pu}$ tests. Currently available correlations shown in Fig. 15 (i.e., those of Marchetti [5] and Kamey and Iwasaki [4]) are limited to cases with $\mathrm{OCR} \geq 1$. According to Fig. $15, K_{\mathrm{D}}$ can become significantly larger than 2 and appears to increase linearly on a $\log -\log$ scale as OCR becomes less than 1 . The unusually large $K_{\mathrm{D}}$ is mainly caused by extremely low $\sigma_{\mathrm{vo}}^{\prime}$. One possible way to avoid this "reversed trend" is to replace $\sigma_{\mathrm{vo}}^{\prime}$ with $\sigma_{\mathrm{vof}}^{\prime}$ in the calculation of $K_{\mathrm{D}}$. This replacement implies that the soil is always normally consolidated, or $\mathrm{OCR}=1$, as $K_{\mathrm{D}}$ is $\leq 2$. In any case, an estimated post-consolidation soil unit weight is required in the interpretation of the test data (in this case, post-consolidation $\gamma / \gamma_{\mathrm{w}}=1.5$ was assumed).

\section{Conclusions}

The experience presented in the paper demonstrated the effectiveness of using differential pressure in overcoming the difficulties in performing penetration tests in extremely soft soil. The change in the depth of water does not affect the differential pressure readings. The $\triangle \mathrm{DMT}$ diaphragm expansion readings are taken immediately above the blade. The results are not affected by the friction of air passing through long pneumatic tubing when performing tests under relatively deep water from a barge. Residual excess pore water pressure existing in the young reservoir sediment can be readily measured using the $\Delta \mathrm{Pu}$. With these test data, it is possible to expand the DMT correlations to soils with $\gamma / \gamma_{\mathrm{w}}$ below 1.6 and OCR less than 1 .

Open Access This article is distributed under the terms of the Creative Commons Attribution License which permits any use, distribution, and reproduction in any medium, provided the original author(s) and the source are credited.

\section{References}

1. Failmezger RA, Anderson JB (eds) (2006) In: Proceedings of the 2nd international conference on the flat dilatometer. DMT 2006, Washington, D.C., p 386

2. Ho YT, Huang AB, Lee JT (2008) Development of a chirped/ differential optical fiber bragg grating pressure sensor. J Meas Sci Technol 19(4):6. doi:10.1088/0957-0233/19/4/045304

3. Huang AB, Lin CC, Chung CC (2008) TDR/DMT characterization of a reservoir sediment under water. J GeoEng 3(2):61-66

4. Kamey T, Iwasaki K (1995) Evaluation of undrained shear strength of cohesive soils using a flat dilatometer. Soils Found 35(2):111-116

5. Marchetti S (1980) In situ tests by flat dilatometer. J Geotech Eng Div ASCE 106(GT3):299-321

6. Marchetti S, Crapps DK (1981) Flat dilatometer manual. Internal Report of G.P.E. Inc.

7. Marchetti S, Monaco P, Totani G, Calabrese M (2001) The flat dilatometer test (DMT) in soil investigations. A Report by the ISSMGE Committee TC16. Proc. IN SITU 2001, intnl. conf. on in situ measurement of soil properties, Bali, Indonesia, May 2001, p 41 